\section{Commentary: Unwrapping the riddle from the enigma}

\author{
Dawn S. Hui, MD
}

Numerous aspects of intramural hematoma (IMH), including initial management strategy and timing of surgery, continue to be debated. Even the underlying pathology remains controversial. Some characterize the etiology strictly as hemorrhage occurring in the tunica media, without an entry tear. Others view this is as a form of acute aortic dissection, termed "non-communicating" or "thrombosed," with the entry tear unable to be appreciated on imaging. Further complicating the matter, IMHs that begin as strictly medial entities may progress to intimal tear and dissection. In a more nuanced view, Lansman and collegues ${ }^{1}$ proposed that the source of flow and resistance of the media are the 2 factors governing whether IMH thromboses or progresses to aortic dissection (Figure 1). As the Japanese Circulation Society 2011 Guidelines acknowledge, the discrepancy between Eastern and Western guidelines is due to this philosophical difference, which cannot be solved without pathologic specimens. ${ }^{2}$ Nevertheless, the operative mortality of IMH and acute aortic dissection is similarly high. Heterogeneity in reported outcomes of medical versus surgical management underpin the ongoing lack of consensus.

In this edition of The Journal, Suematsu and colleagues ${ }^{4}$ report on stepwise external wrapping, a novel surgical approach to manage IMH by adapting a technique that has been used for aneurysmal disease. While hampered by lack of a medical management comparison group, clinical outcomes were excellent in a high-risk group (mean age 78 years, mean European System for Cardiac Operative Risk Evaluation II 54\%), with $0 \%$ inhospital/30-day mortality, 3-year survival of $89.8 \%$, and no aortic-related mortality during follow-up. The surgical

\footnotetext{
From the Department of Cardiothoracic Surgery, University of Texas Health Science Center at San Antonio, San Antonio, Tex.

Disclosures: The author reported no conflicts of interest.

The Journal policy requires editors and reviewers to disclose conflicts of interest and to decline handling or reviewing manuscripts for which they may have a conflict of interest. The editors and reviewers of this article have no conflicts of interest.

Received for publication Aug 26, 2020; revisions received Aug 26, 2020; accepted for publication Aug 26, 2020; available ahead of print Aug 31, 2020

Address for reprints: Dawn S. Hui, MD, Department of Cardiothoracic Surgery, University of Texas Health Science Center at San Antonio, 7703 Floyd Curl Dr, San Antonio, TX 78258 (E-mail: dawn.hui@gmail.com).

J Thorac Cardiovasc Surg 2022;164:39-40

$0022-5223 / \$ 36.00$

Copyright (C) 2020 by The American Association for Thoracic Surgery

https://doi.org/10.1016/j.jtcvs.2020.08.090
}

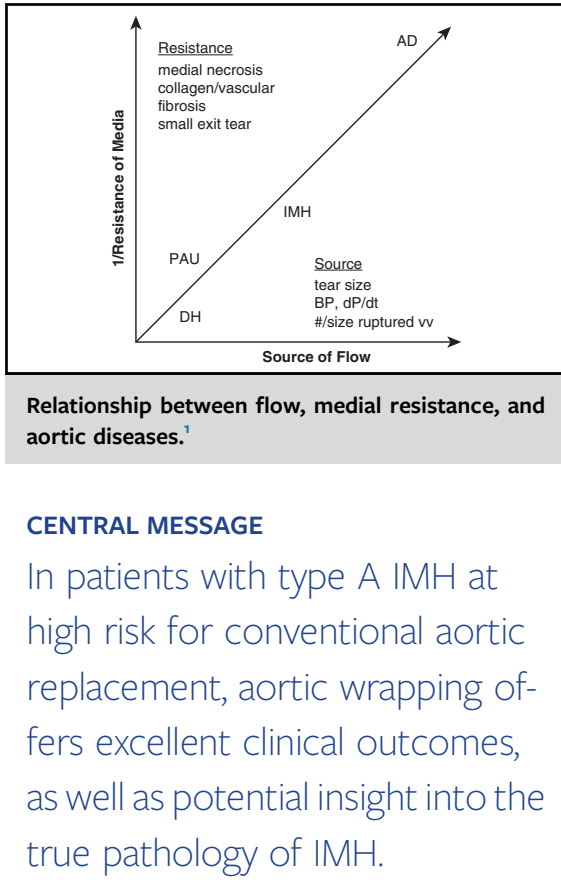

technique of stepwise external wrapping involves significant refinement and innovation over aortic wrapping. As the authors note, development of the plane between the fragile aorta and pulmonary artery requires meticulous care; cardiopulmonary bypass is also likely requisite for

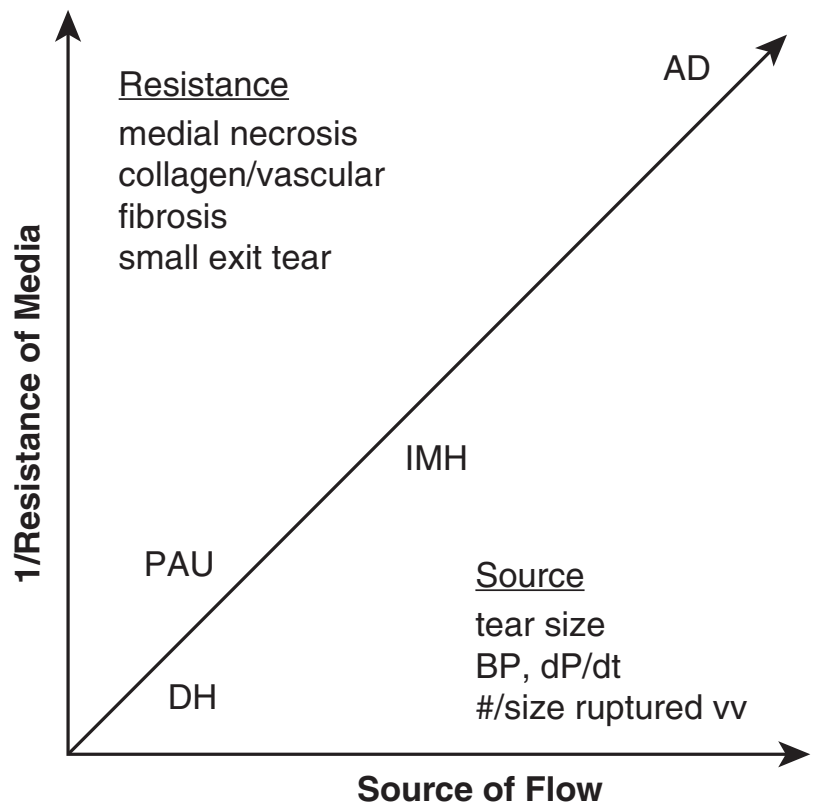

FIGURE 1. Relationship between flow, medial resistance, and aortic dissection. ${ }^{1}$ 
safe dissection. Use of specifically designed instruments facilitated posterior passage of the graft material, and graft pieces were tailored to account for size discrepancies in the various aortic segments.

The long-term aortic outcomes in this series may lend some insight into the question of the likelihood of an entry tear being associated with type A IMH. The immediate biomechanical effect of wrapping is reduction of wall stress in the wrapped segment. However, the compliance mismatch between native and wrapped aorta, due to differential elastic properties, results in increased wall stress in the native aortic segments closest to the wrapped portion. These effects have been demonstrated in computational models. ${ }^{5}$ Just as high wall stress correlates with intimal tear development, local greater wall stress in reaction to wrapping would likely tend to promote continued flow through an existing entry tear. ${ }^{6}$ No patient in the study by Suematsu and colleagues developed an acute dissection after wrapping, and aortic remodeling was $100 \%$ at 2 years. Thus, one could reasonably speculate that these excellent short- and mid-term aortic outcomes suggest the absence of an intimal tear in this series. Nevertheless, just as Suematsu and colleagues acknowledge the need for highquality data to reach persuasive evidence in the clinical realm, much greater computation and biomedical work are needed in the realm of IMH.

\section{References}

1. Lansman SL, Saunders PC, Malekan R, Spielvogel D. Acute aortic syndrome. J Thorac Cardiovasc Surg. 2010;140:S92-7.

2. JCS Joint Working Group. Guidelines for diagnosis and treatment of aortic aneurysm and aortic dissection (JCS 2011): digest version. Circ J. 2013;77:789-828.

3. Sandhu HK, Tanaka A, Charlton-Ouw KM, Afifi RO, Miller CC, Safi HJ, et al. Outcomes and management of type A intramural hematoma. Ann Cardiothorac Surg. 2016;5:317-27.

4. Suematsu Y, Inoue T, Nishi S, Kurahashi K, Arima D, Yoshimoto A. Stepwise external wrapping procedure for type A intramural hematoma. J Thorac Cardiovasc Surg. 2022;164:31-8.e1.

5. González-Santos JM, Arnáiz-García ME. Wrapping of the ascending aorta revisited-is there any role left for conservative treatment of ascending aortic aneurysm? J Thorac Dis. 2017;9(suppl 6):S488-97.

6. Plonek T, Zak M, Rylski B, Berezowski M, Czerny M, Beyersdorf F, et al. Wall stress correlates with intimal entry tear localization in type A aortic dissection. Interact Cardiovasc Thorac Surg. 2018;27:797-801.

\section{Commentary: External wrapping in proximal intramural hematoma of the aorta: What's behind the magic?}

\author{
Christoph A. Nienaber, MD, PhD, ${ }^{a, b}$ \\ Andreas Hoschtitzky, $\mathrm{MD},{ }^{\mathrm{c}}$ and \\ Xun Yuan, MBBS, MMED ${ }^{\mathrm{a}, \mathrm{b}}$
}

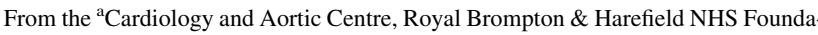
tion Trust, ${ }^{b}$ National Heart and Lung Institute, Faculty of Medicine, Imperial College London, and ${ }^{c}$ Department of Cardiac Surgery, Royal Brompton \& Harefield NHS Foundation Trust, London, United Kingdom.

Disclosures: The authors reported no conflicts of interest.

The Journal policy requires editors and reviewers to disclose conflicts of interest and to decline handling or reviewing manuscripts for which they may have a conflict of interest. The editors and reviewers of this article have no conflicts of interest.

Received for publication Sept 3, 2020; revisions received Sept 3, 2020; accepted for publication Sept 3, 2020; available ahead of print Sept 10, 2020.

Address for reprints: Christoph A. Nienaber, MD, PhD, Cardiology and Aortic Centre, Royal Brompton \& Harefield NHS Foundation Trust; Imperial College London, London SW3 6NP, United Kingdom (E-mail: C.Nienaber@rbht.nhs.uk).

J Thorac Cardiovasc Surg 2022;164:40-1 0022-5223/\$36.00

Crown Copyright $\odot 2020$ Published by Elsevier Inc. on behalf of The American Association for Thoracic Surgery

https://doi.org/10.1016/j.jtcvs.2020.09.023
}

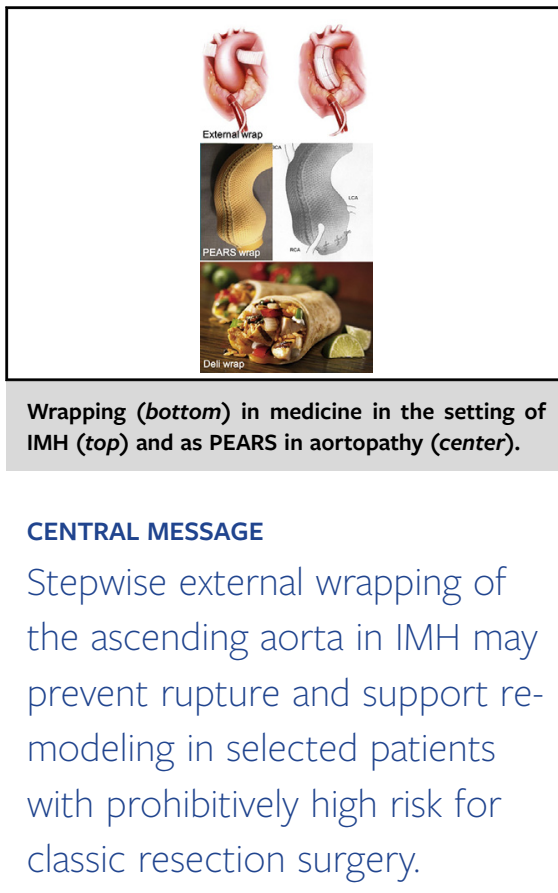

The Department of Cardiovascular Surgery at Tsukuba Memorial Hospital, spearheaded by Dr Yoshihiro Suematsu, 